\title{
O etnólogo pela pena: meditações póstumas sobre escolhas monográficas
}

\author{
Andras Jucksch Ellendersen ${ }^{1}$ \\ Recebido em setembro de 2020 \\ Aceito em dezembro de 2020
}

\section{RESUMO}

Este artigo oferece uma reavaliação crítica do processo de elaboração de $O$ fantasista e o flagelo: sentidos de si e de África para Günther Theodor Tessmann (1884-1969), uma monografia de graduação que se debruça sobre a trajetória de vida de um etnólogo alemão. Por uma perspectiva de bastidores, a abordagem da análise se dará em primeira pessoa, tratando a fundo as vias sinuosas que originam certas escolhas metodológicas, interrogando seus fundamentos subjetivos e suas consequências objetivas para a artesania de um texto que se apresenta como uma contribuição para o campo das ciências sociais.

Palavras-chave: trajetórias de vida; método; pesquisa.

\section{The ethnologist by the quill: posthumous meditations on monographic choices}

\begin{abstract}
This article provides a critical revaluation of the elaboration process of $O$ fantasista e o flagelo: sentidos de si e de África para Günther Theodor Tessmann (1884-1969), a graduation monograph which sets out to study the lifepath of a German ethnologist. From an insider's point of view, the analysis' first-person approach will cover in depth the winding paths at the origin of certain methodological choices, questioning their subjective foundations and their objective consequences for the crafting of a text which presents itself as a contribution to the field of the social sciences.
\end{abstract}

Keywords: lifepaths; method; research.

\section{Introdução}

Quando estas linhas forem publicadas, a monografia que originou este artigo já terá completado seu primeiro aniversário. Numa das salas do $9^{\mathbf{0}}$ andar do prédio da reitoria da UFPR, O fantasista e o flagelo: um estudo de sentidos de si e de África para Günther Theodor Tessmann (1884-1969), orientado pelo Prof. Dr. Paulo Renato Guérios,

\footnotetext{
1 Graduado em Ciências Sociais, com ênfase em Antropologia, pela Universidade Federal do Paraná. Sua atividade como pesquisador na graduação alicerçou-se no estudo de trajetórias de vida, tangenciando aspectos da história da antropologia e do colonialismo na Alemanha. Contato: andras.atlason@gmail.com
} 
foi defendido a 12 de dezembro de 2019 com arguições do Prof. Dr. Rafael Faraco Benthien e da Prof. Dra. Simone Meucci, ambos professores da casa.

Na introdução daquele trabalho, escrita por último, há fragmentos que parecem denotar antes uma justificação que um prenúncio auspicioso, como que dizendo ao leitor: "desculpe qualquer coisa”. Escrevo ali sobre convicções "talvez algo ingênuas" (ELLENDERSEN, 2019, p. 12) e premissas que, "entre outras, apresento [...] menos para defender sua infalibilidade que como uma franca reavaliação a posteriori do texto, dando ao leitor a satisfação [...] de suas potenciais forças e também de suas potenciais limitações" (p. 11) - elementos que tampouco passariam despercebidos na avaliação da banca.

A oportunidade de escrever para um periódico discente trouxe consigo o desejo de, a partir do ponto de vista privilegiado do presente, aprofundar aquela reavaliação expondo circunstâncias internas da pesquisa e algumas das razões pelas quais talvez seja possível encarar o texto, hoje, menos como uma contribuição sólida a seu campo que como um registro de uma etapa de minha incipiente trajetória enquanto pesquisador o que não significa, claro, esvaziá-lo de seu valor.

No que diz respeito ao método, talvez se trate de voltar o feitiço contra o feiticeiro - ou, para ser mais verossímil, contra o aprendiz - e converter-me no objeto da aventura da qual fiz vítima um pesquisador de outra era, debruçando-me sobre as falhas de percurso responsáveis por vícios metodológicos que, à época tão sedutores e enganosamente inescapáveis, hoje enxergo plenamente. Num esforço intelectual de Epimeteu - isto é, em que o agir já precedeu há muito o pensar -, volto ao passado com a presunção de que, bem além de uma autoanálise, o leitor possa encontrar aqui considerações de valia também para outros tipos de pesquisa aos quais se dedique ou venha a se dedicar. Considerações estas que, asseguro, se revelarão de imediato menos impressionistas que esses parágrafos iniciais.

\section{Günther Theodor Tessmann (1884-1969)}

O fantasista e o flagelo se anuncia como um esforço, apoiado sobre uma metodologia microhistórica, para elucidar aspectos da trajetória de vida de Günther 
Theodor Tessmann (1884-1969), um intelectual alemão que construiu para si um nome como etnólogo - ainda que seu empenho científico tenha sido entremeado por uma gama de interesses que, da botânica e da zoologia à astronomia, talvez lhe rendesse, em outra época, a designação mais genérica de naturalista. Neste item, o leitor encontrará menos uma síntese do TCC, a ser abordado mais adiante, que uma narrativa já mais madura - e avolumada por reflexões posteriores, em grande parte despertadas pela banca (à qual sou muito grato) - que talvez melhor sirva ao propósito de introduzir o leitor ao "personagem" Tessmann, a sua multifacetada agência histórica e às fontes que deixou para trás.

Com um diário de 1922, talvez sem saber, Günther Tessmann daria o pontapé inicial da redação de um corpo de textos de memórias de vida que, até a sua morte, quase cinco décadas mais tarde, atingiriam doze volumes. ${ }^{2}$ Beirando seus 40 anos de vida, Tessmann conduzia nessa época um trabalho de campo nas imediações do Rio Ucayali, no Peru, cujos resultados viriam à luz dali a alguns anos em seu 'canto de cisne' na antropologia cultural, a saber, o par de obras americanistas Homens sem Deus (1928) e Os indígenas do nordeste peruano (1930). A recepção controversa de ambas as publicações marcaria o início do fim de sua carreira na etnologia, fim este que se daria menos por um golpe abrupto que por um empalidecimento gradual na vida de um homem que, conforme se dedicava mais e mais à busca de um sentido no universo, ${ }^{3}$ mais

\footnotetext{
${ }^{2}$ Uma vez dispostos os 12 volumes em ordem cronológica, o diário iniciado em 1922 se tornaria o volume VIII, complementado em 1928 pela redação do volume IX, que cobre o restante de seu trabalho de campo peruano (1923-1926). As memórias de vida de Tessmann, armazenadas desde o fim da década de 1960 no acervo da Völkerkundesammlung dos Museus de Lübeck, foram academicamente trabalhadas pela primeira vez por Klockmann em sua dissertação König im weißen Fleck (1988). Mais recentemente, Templin e Dinslage esforçaram-se pela edição comentada integral dos volumes que, até o presente momento, foram publicados pelos Museus de Lübeck até o volume VII (DINSLAGE e TEMPLIN, 2012; TEMPLIN, 2015; DINSLAGE, 2015). Os documentos originais foram integralmente digitalizados pelos Museus de Lübeck e estão disponíveis para acesso no link: <https://vks.die-luebeckermuseen.de/tessmann-tagebuch $>$ Acesso em 24/10/2020, 23 ho9.

3 Em 1950, Tessmann publica em livro um sistema de correspondências numéricas entre dados astronômicos e fenômenos terrestres (i.e. desde processos biológicos até o "ciclo vital" de culturas humanas). O esquema, que Tessmann batizaria O plano da criação [Der Schöpfungsplan], teria sido concebido ainda em 1924 e aperfeiçoado ao longo dos anos até sua publicação em Curitiba, no Paraná. Seu esforço totalizante numa época em que as disciplinas se ensimesmavam com rapidez, aliado ao apego a modelos científicos datados e uma intenção tácita de respaldar cientificamente a cosmogonia cristã, fariam com que $O$ plano da criação enfrentasse o silêncio tanto da comunidade científica quanto da eclesiástica, tornando vãos seus esforços quase obcecados para ter reconhecidos, no fim da vida, os méritos do que entendia como seu "trabalho de vida" [Lebenswerk]. Toda a produção intelectual de
} 
escrevia e lia sobre si mesmo, como que prestando contas sobre uma trajetória de glórias e também de fracassos.

Nascido na cidade portuária de Lübeck, no norte da Alemanha, o etnólogo autodidata foi prática e intelectualmente produtivo na disciplina durante, aproximadamente, as três primeiras décadas do século XX. Menções à etnologia em sua obra tardia, como aponta Fischer (1991, p. 101) em comentário ao seu O plano da criação (1950), já davam sinais de uma desatualização crítica no que toca às não negligenciáveis transformações teóricas e metodológicas que havia sofrido a disciplina nos anos precedentes, mesmo no âmbito da produção em língua alemã - sintoma, talvez, de um período de sua vida em que a ciência cultural já não figurava entre suas primeiras preocupações.

Antes disso, contudo, Tessmann publicaria uma vasta obra etnográfica que, permitindo-se dividir grosseiramente em uma fase africana (1904-1921) e outra amazônica (1921-1933), teve entre seus leitores e comentadores nomes da competência de Frazer, Boas, Lévy-Bruhl, Kroeber, Nimuendajú, Eliade e Lévi-Strauss. ${ }^{4}$

A década de 1930 era aguardada por Tessmann com promissoras expectativas: com sua defesa de um método que batizou de culturologia sistemática [systematische Kulturkunde], Os indígenas do nordeste peruano 5 se propunha o marco inaugural de uma nova era metodológica para a antropologia, acompanhada do projeto de fundação de um

Tessmann posterior a 1950 se resume a complementos, desdobramentos e versões panfletárias dos princípios inaugurados n'O plano.

4 Para uma discussão aprofundada tanto de sua interpretação particular da religiosidade Bantu como dos dados etnográficos trazidos por Tessmann em sua mais extensa obra africanista, Os fangues (1913), cf. Fernandez (1982) e Laburthe-Tolra (1985). Sobre os bastidores da produção dessa mesma obra, cf. Klockmann (1988) e Ellendersen (2019). Sobre suas observações etnográficas da Amazônia peruana, bons apanhados foram trazidos por Tournon (2002) e, sob um enfoque linguístico, Fleck (2003).

${ }^{5}$ Na obra de 1930, Tessmann avança uma comparação extensiva de 50 etnias distintas do nordeste do Peru submetendo-as a uma mesma tabela de 76 itens de análise - e.g. desde formas de habitação até particularidades de comportamento sexual, costumes rituais e jogos infantis. Resulta disso um quadro comparativo de fácil consulta, do qual emergem "famílias culturais"' identificadas pelo autor a partir dos parentescos extraídos da sobreposição comparativa dos resultados. A preocupação subjacente era a de ofertar um método que, em meio à percepção de uma diluição vertiginosa das populações indígenas na cultura ocidental, servisse a uma "antropologia de salvamento" determinada a reunir um grande volume de dados em pouco tempo. Com o passar dos anos, mais de um autor viria a enaltecer a obra menos por sua proposta metodológica que por sua riqueza de dados etnográficos (e.g. SAPPER, 1931), em franco contraste ao que declaradamente desejava Tessmann (1930, p. 41). O volume foi companheiro de viagem de nomes como Nimuendajú e Baldus, permanecendo hoje uma fonte correntemente citada em trabalhos brasileiros e hispanófonos sobre povos amazônicos. 
instituto de pesquisa etnológica em Berlim que teria Tessmann como seu diretor (MILDBRAED, 1930). No mesmo ano de 1930, a Universidade de Rostock concederia a Tessmann, que não havia atravessado qualquer percurso acadêmico formal, um título doutoral honorífico que, abrindo portas para cátedras universitárias para as quais era exigido, ofertaria a possibilidade de uma ansiada estabilidade profissional, passadas décadas de idas e vindas entre a Alemanha e diversos destinos tropicais.

As circunstâncias, contudo, se delineariam de maneira menos auspiciosa. Sua culturologia sistemática encontraria insuficientes entusiastas, e sua etnografia sobre os Shipibo-Konibo, Homens sem Deus, muitos críticos. Se, em razão de seus comentários depreciativos sobre indígenas sul-americanos, se desgastava sua imagem entre figuras influentes do cenário etnológico difusionista alemão, como Pe. Wilhelm Schmidt (18681954), seus textos sobre a homossexualidade africana e sua amizade com o venereologista judeu Hans Haustein (1894-1933) fariam dele persona non grata também entre os nazistas, a despeito do manifesto racialismo expresso em etnografias africanistas suas como Os fangues (1913) e Os bubi de Fernando Pó (1922). Enquanto a perspectiva da almejada posição universitária se tornava pouco a pouco menos nítida, o início da década de 1930 marcaria também o fim de um relacionamento duradouro com Eduard Pape (1903-?), seu companheiro de vida. Como relataria vinte anos mais tarde,

[...] infelizmente, o destino procedeu de modo duro comigo outra vez, fazendo um largo risco sobre os meus cálculos. Esse ano [1931] foi, em absoluto, um dos mais terríveis que já vivi, e o infortúnio que me perseguia jamais havia sido tão grande como nesse maldito ano, o ponto mais profundo da decadência dessa época da vida. $\left(\mathrm{X}: 85^{6}\right) \cdot{ }^{7}$

Talvez fosse sintomático que, logo entre 1930 e 1935, solitário, desempregado e "totalmente empobrecido" (III: 187), Tessmann tivesse escrito os seis volumes (II-VII) de diários cobrindo precisamente o que entenderia em retrospecto como os anos áureos de

\footnotetext{
${ }^{6}$ Como foi o caso na monografia de conclusão de curso O fantasista e o flagelo (2019), as memórias de vida serão referenciadas neste artigo seguindo o modelo já adotado por Klockmann (1988) de indicar em algarismos romanos, entre parênteses, o número do volume separado por dois pontos da indicação de sua página.

7 A monografia que baseia o presente artigo opera com fontes primárias em língua alemã e alguma bibliografia secundária em alemão ou inglês, que optamos por trazer ao leitor em tradução livre, adicionando entre colchetes trechos do original quando a tradução oferece possíveis ambiguidades.
} 
sua vida, quais sejam: os de sua primeira partida à África Equatorial, em 1904; de sua primeira expedição etnológica de grande porte, a Expedição-Fangue de Lübeck (19071909); da publicação da primeira obra científica de sua autoria, Os fangues (1913), e de sua primeira expedição a serviço do Ministério Colonial Alemão na então colônia de Camarões, a Expedição Ssanga-Lobaje (1913-1916), o “ápice de minha vida” (V: 55).

Em paralelo a tais insígnias curriculares, a década inaugural do século XX seria também particularmente rememorada por Tessmann por uma "proeza" extraoficial, a saber, a de sua escalada autoritária em Río Muni, região continental da Guiné Equatorial predominantemente ocupada pela etnia Bantu fangue. Num território à época virtualmente inexplorado por cartógrafos, Tessmann afirma ter edificado, aos 22 anos de idade, uma existência autônoma valendo como autoridade política, ou ainda, segundo seu relato, como deidade entre os indígenas, experiência que sustentaria sua leitura futura de um passado de grandes aventuras nos trópicos e que, já no Brasil, ele reconstituiria em forma de romance em seu autoinspirado manuscrito, O rei na mancha branca (1940).

Com a interrupção da Expedição Ssanga-Lobaje em razão da Primeira Guerra Mundial, com o desfecho do Tratado de Versalhes e a consequente derrocada do poder colonial germânico em 1918, sofria os primeiros baques uma carreira que, até então, havia sido construída em estreita vinculação com a rede ultramarina nacional. Mais tarde, como atestado da postura acrítica que retinha diante do colonialismo europeu, Tessmann faria do período de vigência do império colonial alemão um frequente objeto de nostalgia: um "tempo inesquecível” no qual, "então jovem e pura, [minh'alma] vive e tece", e "hoje canta dele outra vez" (TESSMANN, 1940, p. 64).

O caráter seletivo da memória, que, como ressalta Pollak (1992), se constrói na seleção consciente ou inconsciente da dimensão da experiência vivida que se toma por significativa no momento da rememoração, se verifica sem demora em Tessmann na hipertrofia patente de suas memórias africanas.

A “decadência” dos anos 1930 encontraria uma aparente salvação na Berlinische Boden-Gesellschaft, sociedade negociadora de terras que, gerida por judeus em fuga do nazismo e almejando investir seu capital no exterior (STIER e KRAUß, 2005), apostaria em Tessmann e em seus anos de experiência amazônica (1921-1926) para empregá-lo 
como consultor de terras para o estabelecimento de colonos alemães na América do Sul. Condicionando a empreitada ao escopo da região norte do Paraná - onde Reinhard Maack (1892-1969) ${ }^{8}$, geólogo alemão com quem havia feito amizade na Alemanha em 1928, já havia se estabelecido -, Tessmann viaja ao Brasil em 1936, acompanhado do diretor da companhia, à espera de um desfecho positivo das negociações para dar início à edificação de uma velhice confortável sob novos ares. Ao desembarcar no Rio de Janeiro, uma entrevista concedida ao periódico $O$ Jornal sugere que a culturologia sistemática ainda não configurava, naquele momento, um projeto abandonado:

[...] pretende durante suas excursões não só pelo Brasil como pela America do Sul, proceder a estudos ethnologicos dos indigenas americanos. $\mathrm{O} \mathrm{dr}$. Tessmann, é de opinião, que os estudos sobre os nossos indios deveriam ser sobremaneira intensificados, porque, o desaparecimento das populações autoctonas, é progressivo, no passo que a civilização européa, vae absorvendoas rapidamente. Si continuar assim, um grande manancial de estudos e observações interessantissimas do ponto de vista scientifico, ficará perdido para sempre. [...] (20/11/1936)

Contudo, um entrave na liberação de verbas da Berlinische Boden-Gesellschaft arruinaria suas perspectivas profissionais e o conduziria a adquirir um terreno de mata virgem em um distrito de Apucarana; sua jornada no Brasil começaria com "anos de miséria" como um "colono no inferno verde" (XI: 1). Com o fracasso derradeiro das três alternativas de fonte de renda projetadas para a garantia de sua subsistência, 9 Tessmann parte em 1940 para Santa Catarina, onde — salvo o interlúdio de sua prisão pelo DOPS curitibano, em 1943, no âmbito da fragilidade civil do estrato germânico brasileiro durante o Estado Novo - permanece alternando instáveis ocupações até 1947, quando surge o convite do então diretor do Museu Paranaense, José Loureiro Fernandes (1903-

\footnotetext{
${ }^{8}$ Reinhard Maack (1892-1969) foi um geólogo autodidata e explorador alemão. Formado agrimensor, viaja em 1911 para a colônia alemã Deutsch-Südwestafrika, atual Namíbia, onde trabalha no levantamento topográfico da região até seu recrutamento voluntário para o exército alemão durante a Primeira Guerra Mundial. Após seu retorno à Alemanha, viaja em 1923 a Minas Gerais, no Brasil, para colaborar nas buscas por ouro na região, e no início da década de 1930 por diamantes no norte do Paraná. Destacando-se por estudos geológicos comparativos envolvendo a África e a América do Sul no âmbito da teoria da deriva continental, estabelece-se a serviço do Museu Paranaense e do IBPT em Curitiba, onde falece em 1969. Disponível em: <http://reinhardmaack.de/lebensstationen.html> Acesso: 21/10/2020, 16:17.

9 Eram estes 1) a venda de exsicatas de plantas paranaenses a museus nacionais e estrangeiros, 2) a possibilidade de uma efetivação tardia dos negócios da sociedade de terras e 3) os rendimentos da venda dos produtos de seu trabalho no sítio em Apucarana (X: 306-308).
} 
1977), para que ocupasse uma posição de assistente de botânica no museu da capital do Paraná.

Passados dois anos em que teria conferido "uma moderna e racional organização à secção de botânica, e sobretudo ao incipiente herbário" (STELLFELD, 1949), Tessmann se transfere para o Instituto de Biologia e Pesquisas Tecnológicas (IBPT), onde exerce função similar pelos 5 anos subsequentes até sua aposentadoria, em 1955 - ano de sua única e amarga visita à Alemanha pós-guerra.

O início da década de 1950 traria consigo dois novos volumes de memórias de vida: o número I - de autoria de um Tessmann que, aos 65 anos em meio a uma rotina de coleção botânica extensiva, remonta a época da infância em sua cidade natal enfatizando a descoberta do mundo natural e sua "pura pulsão colecionista" (I: 70) — e o número X - no qual, numa etapa de sua vida em que se descreveria como "finalmente, no alto outra vez" (XII: 121) em razão da alcançada estabilidade profissional, grava no papel a decadência dos desafortunados anos 1930 em Berlim. Após um período de residência fixa na Ilha do Mel, no litoral paranaense, Tessmann vive, em 1958, um último ano em seu sítio em Apucarana antes de se restabelecer em Curitiba, onde viria depois a falecer aos 85 anos de idade.

A promessa de que procederia a "estudos ethnologicos dos indígenas americanos", feita em 1936 a'O Jornal, não viria a se concretizar e, depois de sua chegada ao Brasil, a etnologia não tornaria a merecer qualquer atenção mais expressiva que a de poucas palestras informais entre círculos de colonos em Rolândia (XI: 82) - mesmo a despeito da alegada intenção, expressa ainda em 1942 em carta a Loureiro Fernandes, de publicar um artigo antropológico inédito nos arquivos do Museu Paranaense (TESSMANN, 1942).

Seus últimos anos de vida seriam marcados por uma dedicação exaustiva e quase obcecada à popularização das correspondências planetárias e terrestres que anunciara em seu livro O plano da criação (1950), paralela de um lado ao aprofundamento de seu evangelismo cristão através de cartas e manifestos, e de outro à redação descontínua dos dois volumes restantes de memórias de vida (XI e XII) até sua morte.

Liberal demais para os nacional-socialistas, racista demais para os progressistas, demasiadamente diletante para os acadêmicos e exageradamente naturalista para os 
etnólogos, Günther Tessmann nunca pareceu ter encontrado para si um lar no interior de sua constelação histórica. Como se pode depreender dos parágrafos acima, trata-se de um sujeito que se permite ler a partir de uma miríade de recortes e pontos de vista. Discutiremos, agora, o recorte feito para a monografia de conclusão de curso $O$ fantasista e oflagelo, bem como alguns dos processos por detrás da formatação final que o trabalho acabaria por assumir.

\section{O fantasista e o flagelo}

Introdução e conclusão à parte, a monografia é dividida em 5 capítulos, que, contando suas subdivisões internas, somam 16 blocos de texto. Os recortes temáticos gerais se permitem reduzir, como anuncio em seu resumo, a 1) os sentidos que Tessmann atribuiu a sua prática colecionista; 2) suas escolhas formativas e as associações institucionais que formataram as circunstâncias para seu direcionamento profissional e intelectual; 3) as 'imagens de si' que emprestavam sentido a sua agência como um viajante na África; 4) o imaginário colonial expresso por Tessmann em sua concepção do continente africano e de seus habitantes, bem como 5) sua conexão com o universo oitocentista dos diários de viagem e seu potencial explicativo para elucidar aspectos da epistemologia subjacente à sua ciência.

Em dois sentidos principais, a divisão temática acima desvia do caminho originalmente previsto: primeiro, por contemplar somente metade do plano de trabalho preestabelecido - exatos 6 meses antes da defesa, enviei ao meu orientador um roteiro, aprovado com entusiasmo, de 18 microtemas encerrando um ciclo de reflexões para a monografia (desses, apenas 9 viriam, algo disformes, a compor o texto final) - e, segundo, pela hipertrofia do aspecto personalista - i.e. um foco em "sentidos de si", “imagens de si” e em imaginários "expressos por Tessmann” em detrimento de potenciais sentidos objetivos a serem apontados no limiar entre sua agência e o campo social e intelectual em que agia.

Se, por um lado, é certo que todo percurso de pesquisa, guiado pelos “imponderáveis da vida real”, guarda sua porção de atalhos sinuosos - sobre os quais fui, e não pouco, alertado -, há também que se aferir, sem rodeio, sua fronteira para com os 
ponderáveis descaminhos que, muito mais que preciosas anedotas acadêmicas, nos trazem ensinamentos para o futuro.

Desde logo, é importante mencionar que O fantasista e o flagelo foi o primeiro grande resultado de uma pesquisa que se iniciou ainda em 2017, quando, na condição de orientadora de meu estágio no Setor de Arqueologia do Museu Paranaense (MUPA), a Dra. Claudia Parellada me introduziu a esse esquecido personagem da história paranaense - e que havia sido, conforme descobri em seguida, amigo pessoal de meu avô João Rodolfo Jucksch (1914-2006). Uma vez feita a escolha de torná-lo tema de TCC, o comprometimento com a pesquisa passou a ser, à minha maneira, absoluto: uma caça incansável por PDFs sobre assuntos tangenciais ao tema - separados por pastas para subtemas -, aquisição de livros, fotografias, artigos, visitas a arquivos públicos brasileiros, e-mails a arquivos estrangeiros, a diferentes instituições pelas quais Tessmann passou e a autores de diferentes gerações que escreveram sobre ele - além de, em paralelo, um esforço de recuperação do domínio da língua alemã, com a qual tive contato desde berço, ainda que mais tarde o tenha perdido, e na qual haviam sido redigidas a maior parte de minhas fontes.

Entre 2018 e 2019, a pesquisa se desenvolveria ainda no âmbito do PIBIC (Programa Institucional de Bolsas de Iniciação Científica), também sob orientação do Prof. Dr. Paulo Renato Guérios, abarcando este período também - num “desvio de rota” em meio a uma viagem de férias - uma visita a Lübeck, cidade natal de Tessmann, onde, além da pesquisa em arquivos, também ofertou-se a possibilidade de uma conversa pessoal com Dr. Thomas Klockmann (1954-), autor da primeira publicação de peso dedicada à vida do etnólogo alemão. Descendentes de parentes e de amigos próximos de Tessmann também foram identificados e contatados em ambos os lados do Atlântico, permitindo acesso a todo outro corpo de materiais empíricos, além de constituírem vínculos extremamente valiosos por si sós.

São dados que trago não apenas como um relato de bastidores, mas como sinais de que, por várias razões, eu havia abraçado o projeto do TCC com uma garra, até então para mim, descomunal. Talvez a principal razão fosse - não tão diferente do próprio Tessmann quando publicava sua obra inaugural aos 29 anos - que eu o concebesse menos como um simples trabalho de conclusão de curso que como uma oportunidade 
para, ainda em "tenra idade", publicar um trabalho denso, que exprimisse maturidade, articulasse com propriedade uma vasta e complexa gama de episódios e de perguntas, e até pudesse, quiçá, suscitar de imediato importantes consequências rumo à conquista de um espaço no campo das ciências humanas. Vencido o calendário de disciplinas, optei por estender ainda por seis meses minha graduação para dedicá-los exclusivamente à escrita do que, eu imaginava, seria "mais" que um TCC. Porém, por vezes, é preciso antes dar o passo para então dar-se conta do tamanho da própria perna, motivo pelo qual me volto agora aos perdoáveis deslizes por detrás de um - bom - TCC - e tão somente isso.

\section{A autópsia da obra do ponto de vista do autor}

Talvez a principal causa das singulares deficiências daquele texto, e da qual certamente derivam boa parte das demais, seja a de que, em boa medida, trata-se de um trabalho escrito em clandestina reclusão. A expressão jocosa qualifica meu esforço tácito, à época, para - em parte por um excesso de confiança em meus autoinfligidos palpites metodológicos, em parte pelo medo do transtorno que uma abertura à opinião externa pudesse causar ao frágil edifício que eu havia erguido - evitar uma comunicação franca e constante com meu orientador sobre as movimentações em meu intelecto. Seguindo uma fórmula de alto risco, prevalecia minha intenção de seguir trabalhando no texto em silêncio até que, no resultado final, como que por feitiço, transparecessem os méritos de uma série de escolhas que eu havia feito por conta própria e de cujos fracos alicerces me havia convencido. Falemos, pois, dessas escolhas - primeiro a partir de um olhar em primeira pessoa para, em seguida, fazê-lo do ponto de vista do texto em si.

A primeira delas foi dar ao campo da empiria o primado epistemológico sobre a pesquisa. Isso começava pelo compromisso de levantar os problemas de pesquisa sempre a partir dos dados e nunca, de fora, projetar os primeiros sobre os segundos. Em princípio, essa escolha não só era muito acertada em si mesma como vinha de cima: a linha de pesquisa adotada por meu orientador - e na qual estava inserido meu projeto tinha, entre seus pilares metodológico-analíticos, ao lado da Sociologia do Conhecimento de Mannheim e Merton, a microhistória de Giovanni Levi et alia, e com ela seu esforço para reconstituir e, não raro, contestar as macronarrativas socio- 
históricas testando sua eficácia a partir do "nível do chão" (REVEL, 1996) - ou, em outros termos, do nível dos dados, e até mesmo dos mais singelos. Porém, aquele preceito que, não há dúvida, oferecia um ponto de partida muito agudo para a construção de uma análise, viria a tornar-se, pouco a pouco, um fim em si mesmo em meu modus operandi cada vez mais absorto em revolver os dados em busca de um sentido que, propriamente, em derramar sobre eles alguma luz.

Isso se deu por múltiplos fatores. Um deles era certamente o obstáculo da língua, que tornava por vezes moroso o esforço de superar as fontes primárias. Se, por um lado, e talvez não sem razão, eu me atinha à busca incessante por novos dados que pudessem (e o faziam) revelar novas facetas do objeto sobre o qual me debruçava, o volume sempre crescente de materiais para processar e compreender numa língua estrangeira freava o ímpeto por grandes saltos analíticos - os coágulos de polissemia, que se formavam com rapidez, tornavam traiçoeiro o terreno, tão importante para uma análise de fôlego, das sutilezas semânticas; ou assim me parecia. Isso significa dizer, talvez, que a tarefa estipulada de levantar os problemas começando de baixo me resultava menos fácil do que antes se havia me apresentado, embora eu não me desse conta disso o bastante para recorrer a socorro externo, ou mesmo para tomar, enquanto havia tempo, a mais simples e manifesta das vias: reduzir, e drasticamente, o escopo da pesquisa.

Ao contrário: conforme eu percorria os diários, as muitas obras etnográficas, os artigos, a correspondência privada, os textos de comentadores e o restante daquilo que instituía um verdadeiro acervo sobre aquele etnólogo (cuja história se entrelaçava na brasileira em tão franco contraste com seu oblívio na literatura local), mais eu me convencia de que a profusão de materiais tão diversos constituía não a fraqueza, mas sim a força do trabalho que eu vinha gestando, seduzindo-me a ideia de compartilhar com o público tantos dados de valor quanto fosse possível.

Diante disso, o empenho para mobilizar as fontes a serviço de um texto analítico - informado fundamentalmente também por fontes secundárias e textos teóricos -, se deslocava gradualmente para segundo plano, empalidecendo diante do compromisso de dar àquele disforme acúmulo de informações uma mera organização, separando-o por categorias, identificando seus eixos centrais, na esperança de que, uma vez destacadas 
do caos diacrônico de sua disposição original e postas de maneira clara e distinta, as fontes fossem capazes de despertar algum potencial adormecido - um resultado, como exprimo na introdução da monografia, de uma "confiança talvez algo ingênua no potencial das fontes para falarem de si próprias" (ELLENDERSEN, 2019, p. 12).

Essa confiança ingênua, que tomada por si mesma não talvez não resulte senão absurda, expressava, no entanto, um estado mais profundo de confusão que se instaurava em minha mente conforme eu aprofundava o contato com o material empírico - e que, por mais pessoal que aparente ou resulte esse testemunho, talvez toque numa seara algo insondável mas que, em maior ou menor grau, se faz certamente presente em toda pesquisa: a saber, a da disposição anímica do pesquisador diante dos problemas que pesquisa, bem como dos efeitos daquela disposição sobre suas inclinações epistemológicas, sobre seu mecanismo interno de formulação de perguntas e sobre sua certeza de que sejam aquelas - e não outras - as perguntas a serem feitas.

Debruçar-se sobre uma trajetória de vida, em especial sobre a de um sujeito que, como Tessmann, escreveu quase mais para si próprio que como um intelectual público - e que, mesmo em sua mais ambiciosa publicação científica, parecia dialogar mais consigo mesmo que com qualquer outro -, traz consigo suas armadilhas do ponto de vista delineado acima, ainda que de maneira muito mais sutil e imperceptível do que essas linhas talvez façam crer. A despeito do esforço, que jamais havia sido negociável de minha parte, para manter o que eu entendia como uma distância analítica do objeto, o envolvimento estreito com os anseios, as aspirações e as decepções de um sujeito que venceu e fracassou despertava em mim, silenciosa, uma faísca de desconfiança por leituras dispostas a sobrepor àquele testemunho uma explicação demasiadamente externalista - ou até mesmo qualquer explicação exclusivamente sociológica.

Pouco a pouco, passei a ver-me confortável com a perspectiva de trabalhar quase que só com as fontes primárias sob a crença, injustificada e obscura (mas, à época, atraente), de que ao menos uma boa porção da verdadeira "Verdade" estava lá, nas fontes, e não cá, com o analista - e que, talvez, bastasse revirá-las o suficiente para encontrá-“La”. Tateando por essa hesitação, não tardei a encontrar, no próprio universo da microhistória e suas imediações, refúgios bibliográficos nos quais eu pude me abrigar para justificar tais ideias - e que, embora influentes nos bastidores de sua formatação, 
só não aparecem explicitamente na monografia em razão das reviravoltas que caracterizaram a fase final da redação do texto.

De Carlo Ginzburg (1939-) - nome central na microhistória, mas que adota uma linha de investigação diversa da de Giovanni Levi, preferida por meu orientador - e seu eloquente método indiciário, ou "método das pistas" (1979), assumi a ideia de que a acuidade de uma análise se verificaria antes pela argúcia do olhar de um "detetive”, que perscruta as fontes e identifica suas peculiaridades, que por sua elucidação por suportes teóricos de fora. De Paul Ricœur (1913-2005) e seu conceito de "identidade narrativa” em especial por ter sido identificado numa literatura recente como uma alternativa hermenêutica ao reducionismo sociológico do Bourdieu da "ilusão biográfica"ıo (cf. TRUC, 2011) - emprestei a noção de que aquilo que Tessmann dizia de si próprio, mais que um discurso localizado a ser "desmascarado" pelo cientista social, portaria um valor inerente para uma compreensão profunda da sua pessoa - uma pessoa que se constrói, também, em seu discurso de si. Que não se culpe nem o primeiro, nem o segundo autor pelo mau emprego que fiz de suas palavras - e muito menos meu orientador, que desses movimentos mal havia sido comunicado.

Desse solipsismo epistemológico, germinou, no âmbito do método, um processo que hoje entendo como uma compartimentação do material empírico. Passei a dirigir meu olhar através de certos filtros temáticos entendidos como recorrentes no corpo de fontes deixadas por Tessmann (pretensos “indícios” ginzburguianos), reunindo trechos por suas qualidades comuns - e.g. especificidades de sua teoria antropológica, sua postura para com certos campos institucionais, traços de seu comportamento social, etc. - e convertendo-os gradualmente em narrativas para recortes capitulares. Desse agrupamento de dados que possibilitou, não há dúvida, alguns apontamentos que nada tinham de insignificantes e também outras reflexões agudas, eu me acreditava, contudo, capaz de, após meses peneirando a pilha empírica a esmo, extrair o óleo essencial de tudo o que caracterizaria Tessmann e sua existência no mundo. Desse esforço, resultariam os

10 "Not only does the sociological shift' from Bourdieu to Ricœur lead from a sociology of habitus to a ,psychological sociology ${ }^{e}$ of plural individual singularities but also it leads from a critical sociology to a sociology of critics, that is, a moral and a political sociology." (TRUC, 2011, p. 161) 
18 itens de análise que, agrupados em 6 capítulos, viriam a compor o plano de trabalho que disparou a escrita da monografia.

Entretanto, por um misto entre um ritmo notadamente vagaroso de redação e a falta de lucidez analítica incorporada ao processo, o plano não tardaria a revelar-se de difícil execução. O primeiro choque nessa desabalada carreira de lapsos se daria na primeira versão do texto que, contando já com 65 páginas e a um mês do prazo de entrega, enviei ao Prof. Dr. Guérios, cuja mais que justificada reação de desconcerto e preocupação viria acompanhada de uma série de recomendações de leituras teóricas na esperança de que me fosse possível sofisticar o trato dos dados a tempo. Para mim, um baque - e um par de dias para processar reavaliações não poucas.

Contudo, apartado de seu estado de pura disposição para a exploração crítica, o material de tal forma compartimentado e inflexível havia tornado, num dado momento, quase impossível uma readaptação a novas circunstâncias de pesquisa. $\mathrm{O}$ mês final da redação justaporia uma pane mental ao imperativo da escrita sob a intimidação do calendário. Do resultado, já não se poderia esperar nada que não fosse algo disforme, a despeito dos esforços finais para controle de danos. A constatação de que já não haveria tempo hábil para a escrita do plano completo decretaria, assim, seu curso rumo à incompletude, em vários níveis - desde lacunas no padrão de abordagem analítica e a falta de um fechamento conciso para a estrutura adaptada do texto até, no que talvez tenha sido seu delito mais infeliz, uma apresentação demasiado incompleta do etnólogo Günther Tessmann pela pena deste autor.

\section{A autópsia da obra tal qual resultou}

Passados alguns meses e reconquistada uma certa distância em relação ao olho da tempestade, torna-se mais fácil uma avaliação fria do texto tal como ele resultou. De modo a melhor visualizar a maneira como os eventos relatados mais acima se refletem no caráter da monografia terminada, procuro neste item fornecer respostas a algumas poucas, mas, assim entendo, sensíveis perguntas: qual é o Tessmann que emerge da narrativa que construí no TCC? De que maneira são formulados e investigados, naquele trabalho, os problemas de pesquisa? Que consequências trouxe o excesso de 
"personalismo" para o texto? E, ainda, qual é a natureza do conhecimento que acredito ter produzido através das condutas de pesquisa que adotei?

A construção do personagem Tessmann, em O fantasista e o flagelo, passa muito pelo processo, descrito mais acima, de compartimentação sofrido pelos dados empíricos. As rígidas categorias haviam sido definidas não como perguntas analíticas direcionadas ao material, mas na base da mera reunião de dados sob algum aspecto comum - um processo que, conforme hoje entendo, pode tanto revelar no material alguma ordem antes oculta ao olho nu, como pode também impor a ele suas próprias distorções ao separar o que deveria estar unido ou unir aquilo que não havia razão para separar.

Uma operação de risco, portanto, e que se aplica da mesma maneira à produção do retrato de uma pessoa: se optamos por quebrá-la em partes, tratando cada parte em irremediável isolamento, talvez nosso gesto seja capaz de negar a um só tempo o que há de unidade e o que há de plena multiplicidade em todo sujeito. Nesse sentido, embora disfarçado de acuidade analítica, o efeito principal do encarceramento individual de cada "categoria analítica” parece ser antes blindá-las do único processo capaz de delas extrair um sentido importante: o seu confronto mútuo. Contudo, não há qualquer encenação desse confronto em O fantasista e o flagelo.

Bem, mas ainda que não plenamente confrontados uns com os outros, quiçá pudessem os recortes capitulares derivar sua justificação de serem atravessados por perguntas de pesquisa, que instituíssem uma certa direcionalidade inquisitiva ao trabalho como um todo; de serem, aqueles recortes, abordados no texto sob preocupações subjacentes comuns e conduzidos por uma voz analítica que, ainda que se dedique a um elemento de cada vez, se prove a todo momento ciente do quadro mais amplo de que extrai cada figura.

Pois, outra vez, não foi esse o caso em minha monografia de conclusão de curso. Ao invés de abordar, em partes, Tessmann e sua agência no mundo, o que fiz foi abordar partes destacadas de Tessmann e de sua agência no mundo. Numa palavra, a fragmentação figura menos como uma ferramenta analítica que como um dado intrínseco ao objeto de pesquisa, tal como foi construído. O produto disso é um Tessmann que, menos como o sujeito complexo que busquei apresentar páginas atrás, se apresenta antes como um arremedo de vários pequenos "falsos Tessmanns". 
Tessmanns que, sem propriamente explicá-lo, reduzem e o simplificam o homem: um colecionista que não conversa com o etnólogo, que é aparentado do racialista mas que, por sua vez, desconhece o homossexual e o crente. Uma irresoluta pilha de antagonismos. Uma dialética sem síntese.

A despeito disso, a clara cisão interna que, não há dúvida, caracterizava Günther Tessmann, não é em parte alguma enunciada como um problema a ser resolvido no texto. Que a monografia final tenha contemplado, afinal, apenas uma porção das categorias de análise originalmente previstas, não faz senão agravar esse problema, não concedendo nem mesmo ao leitor a oportunidade de resolver, por si próprio, as névoas de contradição que o separam de um entendimento mais global daquilo que Tessmann representou socialmente e produziu em vida. Em vista disso, o retrato final, ainda que detalhado e pleno de boas intenções, resultou sobremaneira mais enviesado do que seria aceitável para um trabalho de fôlego, deixando muito por dizer. ${ }^{11}$

Essa taciturna constatação nos convida a retomar a reflexão sobre a pesquisa naquilo que ela tem de mais fundamental: como foi que coloquei perguntas para o material com que estava trabalhando? Ou, para cavar mais fundo, será que estive no controle do processo de formulação dessas perguntas? A impressão que hoje tenho, embora eu não evoque em absoluto a pesquisa como um processo estéril de ideias, é a de um texto que não sabe o que quer, e que acabou por fazer-se refém de suas próprias escolhas. Isso porque o ordenamento de recortes temáticos, ainda que num ou noutro caso se aproximasse disso, não correspondia a um ordenamento de problemas de pesquisa. Há, ali, agrupamentos de fontes similares que, não contentes em servir de pontapé inicial para reflexões mais amplas, constituem o texto. Figuram, em vários momentos, como seu ponto de partida e de chegada; sua motivação, seu meio e seu fim.

\footnotetext{
"Como resultado da abordagem, o trabalho de conclusão de curso acabou por privar o leitor da ciência, até mesmo superficial, de aspectos tão importantes de seu testemunho de vida quanto: 1) os fundamentos de sua teoria etnológica em suas diferentes fases, 2) sua homossexualidade e o trato da sexualidade em sua obra, 3) sua busca platônica pelo "princípio originário" do universo, 4) a relação que construiu com seus pares na etnologia alemã e as razões para o desgaste institucional que motivaria sua emigração para o Brasil, 5) as razões por trás da percepção particularmente desfavorável que construiu sobre a América e os indígenas sul-americanos, e 6) a postura que assumiu como um alemão no Brasil e as implicações dessa postura para a compreensão de aspectos de sua obra tardia.
} 
Em se tratando de um trabalho documental em que a maior parte das fontes é escrita em primeira pessoa, há um risco inerente ao procedimento descrito no parágrafo anterior: a saber, o de incutir no texto, como que por contrabando, um excesso de personalismo. Uma intrusão sutil que facilmente se converte numa quimera. Se aquilo que chamo "fontes" se limita, como era o caso, em grande medida à voz de Tessmann, a consequência natural da primazia que lhe conferi no texto foi a de que, de tal forma capturado, meu próprio discurso como autor passou a se fundir, por vezes indistintamente, no discurso do sujeito pesquisado.

A confusão que o texto transmite não derivava, contudo, de uma genuína adesão cega ao ponto de vista de Tessmann por parte do autor: o delito - menos grave, mas com sequelas igualmente nefastas - havia sido o de estruturar e guiar meu texto basicamente através de sua voz. Sem que fosse mobilizado por uma preocupação minha, o ordenamento de fontes acabou por cristalizar-se, no texto, como uma mera ordenação de momentos de subjetividade do próprio Tessmann.

\section{Os ensinamentos para o futuro}

Com um plano de trabalho construído sem uma teoria incorporada, a percepção derradeira de que o texto carecia de análise me colocou diante da tarefa afobada de reconstituir a ponte entre dois campos que, desde o início, haviam sido concebidos em separado. Isso acabaria por tolher minha própria voz analítica, em suas raras, mas não ausentes manifestações. A plataforma estanque que pautava os rumos da escrita pouco previa de liberdade para reflexões francas sobre o objeto, e, mesmo nos limites em que o fazia, meu despreparo teórico - resultado da exclusão da teoria da lista de prioridades - acabava por tornar minhas próprias análises expressões antes da relação orgânica que eu mesmo havia estabelecido com aquelas fontes que de uma ótica bem fundamentada.

Tratava-se, portanto, de um personalismo de duas vias - a de Tessmann, e a minha. Quem perde com isso, não há dúvida, é a ciência social, que assistiu nascer não a um especialista em Tessmann e seu entorno intelectual, institucional e social, mas a um especialista num Tessmann sem esse contexto - o Tessmann das aflições, dos desejos e dos devaneios. Se, conforme apontou em sua arguição o Prof. Dr. Benthien, a natureza 
de minha pesquisa se constitui na dicotomia entre o geral e o particular, um de meus pesares hoje é o de que a balança tenha favorecido tanto o particular, com uma exploração muito pouco fecunda até dos fenômenos que habitam os numerosos interstícios entre tais polos dicotômicos.

As lições que ficam disso, e que espero, seja qual for, que tenham também alguma valia para além de minha experiência pessoal, são certamente muitas, mas, até por isso, devem ser claras.

Primeiro, a de que não se pode ditar, nem acelerar, o ritmo de nosso próprio amadurecimento: a realidade se imporá como uma avalanche, e, desde que exista disposição para tal, suas expectativas não tardarão a harmonizar com a etapa que lhe cabe em sua própria trajetória.

Segundo, a de que a despretensão para projetar francamente sua capacidade de trabalho é um passo crucial para a seleção de recortes acertados de pesquisa: em $O$ fantasista e o flagelo, não há senão um mais que vívido exemplo de alguém que, de tanto querer fazer, muito pouco fez.

Terceiro, a de que, ainda que isso signifique simplificar a análise, é inegociável pisar sempre em solo firme quando o assunto é teoria e metodologia; que se busque aplicar somente aquilo que se compreende, recorrer a tutela se preciso e não se aventurar em palpites a esmo.

Quarto, a de que a academia não constrói seus rituais por capricho, e que fazer valer sua dinâmica e hierarquia tende a beneficiar a produção científica; que orientadores existem para que deles se busque orientação, e que dificilmente bons frutos nascerão de qualquer pretenso autonomismo intelectual que resista a pôr à prova suas ideias.

Por fim, assinalo apenas que, a despeito do esforço de cutucar, antes que estanque, a ferida aberta de meus descaminhos metodológicos, o leitor que vencer estas linhas estará sem dúvida bem munido de ferramentas para extrair também o que pode oferecer de bom uma leitura da monografia de graduação O fantasista e o flagelo - um trabalho documental que traz um grande e valioso volume de dados e cujo vexatório vilipêndio jamais esteve entre os propósitos desse artigo. 
Registro também um especial agradecimento ao Prof. Dr. Paulo Renato Guérios, à Prof. Dra. Simone Meucci e ao Prof. Dr. Rafael Faraco Benthien por, evidentemente cientes dos deslizes imaturos - mas também das forças - daquele que veio a ser meu primeiro grande texto acadêmico, só souberam fazer crescer, com suas encorajadoras palavras, a faísca de minha vontade para pensar - e produzir - cada vez melhor.

\section{Referências}

DINSLAGE, Sabine (org.). Günther Tessmann. Mein Leben - Tagebuch in 12 Bänden (Teil 3). Lübecker Beiträge zur Ethnologie, Band 4. Lübeck: Schmidt-Römhild, 2015.

; TEMPLIN, Brigitte (org.). Günther Tessmann. Mein Leben - Tagebuch in 12 Bänden (Teil 1). Lübecker Beiträge zur Ethnologie, Band 2. Lübeck: Schmidt-Römhild, 2012.

ELLENDERSEN, Andras J. O fantasista e o flagelo: um estudo de sentidos de si e de África para Günther Theodor Tessmann (1884-1969). Monografia de graduação. Universidade Federal do Paraná, 2019.

FERNANDEZ, James W. Bwiti: An Ethnography of the Religious Imagination in Africa. Princeton University Press, 1982.

FLECK, David William. A grammar of Matses. Tese de doutorado. Rice University. Houston, Texas: 2003.

FISCHER, Hans. Völkerkunde im Nationalsozialismus: Aspekte der Anpassung, Affinität und Behauptung einer wissenschaftlichen Disziplin. D. Reimer, 1991.

GINZBURG, Carlo. Clues: Roots of a Scientific Paradigm. Theory and Society, Vol. 7, No. 3, pp. 273-288. Springer. 1979.

KLOCKMANN, Thomas. Günther Tessmann: König im weißen Fleck. Das ethnologische Werk im Spiegel der Lebenserinnerungen. Ein biographischwerkkritischer Versuch. Hamburg: Universidade de Hamburgo, 1988.

LABURTHE-TOLRA, Philippe. Initiations et societes secretes au Cameroun: Les mysteres de la nuit. (Hommes et Societes). 1985.

MILDBRAED, Johannes. [Carta sem destinatário] 20 de janeiro de 1930.

POLLAK, Michael. Memória e Identidade Social. Estudos Históricos, Rio de Janeiro, vol. 5, n. 10, 1992, p. 200-212. 
REVEL, J. 1996. Microanálise e construção do Social. In Jogos de Escala: a experiência da microanálise. Rio de Janeiro FGV, 1998.

SAPPER, K. Resenha de Die Indianer Nordost-Perus. Geographische Zeitschrift, 37. Jahrg., 5. H., pp. 312-314. Franz Steiner Verlag. 1931.

STELLFELD, Carlos. [Carta a Erasmo Pilotto]. Correspondências recebidas e expedidas do Museu Paranaense. Curitiba, 15 de dezembro de 1949.

STIER, Bernhard e KRAUß, Martin. Drei Wurzeln - ein Unternehmen. 125 Jahre. Bilfinger Berger AG. 2005.

TEMPLIN, Brigitte. (org.). Günther Tessmann. Mein Leben - Tagebuch in 12 Bänden (Teil 2). Lübecker Beiträge zur Ethnologie, Band 3. Lübeck: Schmidt-Römhild, 2015.

. „O Mensch, erkenne Dich selbst“ - Richard Karutz (1867-1945) und sein Beitrag zur Ethnologie. Lübecker Beiträge zur Ethnologie, Band 1. Lübeck: Schmidt-Römhild, 2010 .

TESSMANN, Günter. Die Pangwe: völkerkundliche Monographie eines westafrikanischen Negerstammes. Ernst Wasmuth, 1913.

. Die Bubi auf Fernando Poo. Völkerkundliche einzelbeschreibung eines westafrikanischen Negerstammes. Folkwang. 1922.

Menschen ohne Gott. Ein Besuch bei den Indianern des Ucayali. Veröffentlichung der Harvey-Bassler-Stiftung, Völkerkunde, Band I. Stuttgart: 1928.

- Die Indianer Nordost-Perus. Grundlegende Forschungen für eine systematische Kulturkunde. Veröffentlichung der Harvey-Bassler-Stiftung, Völkerkunde, Band II. Hamburg: 1930.

. König im weißen Fleck. Manuscrito de 1940 com alterações posteriores. Acervo da família Zeidler, Curitiba.

. Der Schöpfungsplan und seine Entwicklung im Aufbau unserer Welt. Zwei Bände. Curitiba: Impressora Paranaense, 1950.

. [Carta a José Loureiro Fernandes]. Correspondências recebidas e expedidas do Museu Paranaense. Brusque, 10 de dezembro de 1942.

TOURNON, Jacques. La merma mágica. Vida e historia de los Shipibo-Conibo del Ucayali, Lima, CAAAP, 2002. 
TRUC, Gérôme. Narrative Identity against Biographical Illusion: The Shift in Sociology from Bourdieu to Ricœur. Études Ricoeuriennes/Ricoeur Studies 2 (1):150-167. 2011. 